\title{
DECENTRALIZATION AND EXPECTED TIME IN OFFICE. THE EFFECT OF DECENTRALIZATION ON CABINET DURABILITY
}

Adrian BODEA, PhD

Faculty of Economics and Business, University of A Coruña, Spain

a.bodea@udc.es

José Manuel SÁNCHEZ SANTOS, PhD

Faculty of Economics and Business, University of A Coruña, Spain

jose.manuel.sanchez.@udc.es

\begin{abstract}
The objective of this study is to analyze the role played by both fiscal and political decentralization as determinants of the expected time in office, understood as the latent (unobservable) durability of the cabinets. Using data for all the EU member states for the period that spans from 2007 up to 2017 and employing two competing survival analysis models, namely Weibull (parametric) and Cox (semiparametric), the results show that, even after controlling for other relevant variables (such as majority in legislative, the number of parties in government, the range between the most distant positions in coalition, etc.), decentralization (either fiscal or political) seem to be insignificant over the expected time in office of the cabinets. To the best of our knowledge there is only one study that focused on testing this kind of relationships, but which only considered the case of regional parties with portfolio positions (thus losing sight of the very important "supply and confidence agreements"). The originality of this works stems from the fact that we are more inclusive and that we employ new data and new variables that are more appropriate for framework of European politics, dominated by the anti-EU and populist debates, since the Great Recession of 2008.
\end{abstract}

Keywords Decentralization; Cabinet Durability; European Union.

\section{Introduction}

Regional parties that have won seats in national parliaments are in many countries parties that usually support the government no matter the political ideology. Sometimes their role is emphasized by the fact that they are crucial in determining the majority, thus having a very decisive word in the stability of the political landscape. Furthermore, due to the fact that their main political interests are related to autonomy-centralization debate, they present a relatively flexible left-right 
voting behavior, making them easy coalition partners for big national parties in the central legislatures.

The main hypothesis that we put to the test here is that an increased relative power of the regional political parties in the national parliaments will determine an unstable political landscape and will shorten the lives and expected time in office of the cabinets due to the pivotal roles in majority making and due to their relatively flexible left-right voting behavior in this context.

By looking at raw data on the index represented in Figure 1 we can notice, apart from the obvious high variance among EU countries, very high levels of decentralization in Germany, France, Spain and Belgium. But, checking the values these countries register in terms of mean cabinet duration for the same period (Figure 2) we might be surprised to see that only two of them (Belgium and France) are relatively politically unstable, while the other two seem to register medium to high values of political stability.

Contrasting these facts with the information comprised in the statistics regarding the mean share of regional parties (Figure 3) we notice again the case of Belgium which supports the main hypothesis of our study and that of Romania, which even if it registered a low level of fiscal decentralization, it has a relatively big share of regional parties in the national parliament and quite an unstable political environment. Still, there are other two noteworthy observations that seem to refute it (Spain, Bulgaria).

It is obvious from the analysis of raw data that the relationship proposed by the main hypothesis seems inconclusive and that a more rigorous in depth analysis of this nexus is required. The rest of the analysis is structured as follows: the second part will treat the literature regarding the issue of decentralization, while the third one will be dedicated to the ample and long spanning debate of cabinet survivability from political science; the fourth one is the exposition of our research design together with the main research hypothesis, assumptions and methodology, followed by a fifth part dedicated to the interpretation of the results and discussion on the margin of them. The last part is dedicated to conclusions and future prospects regarding this research.

\section{Decentralization - Debates over definition and measurements}

Decentralization refers to the extent to which the locus of political power, i.e. actual policymaking, lies with the local/regional executives and legislatures in a country (Clark, Golder, \& Golder, 2013p. 684). It is not necessarily a characteristic of federal states only, as opposed to 
the unitary ones. It is true that in the case of a federal state each level of government has the authority to act independently of the other in at least one policy realm, but this does not suffice for a decentralized polity; imagine a state where many policies are prerogatives of local governments, but where the fiscal aid for implementing them comes only from the central government. In this case, the central government could, at any time, retain all the funds and leave the regions without any implemented policies. This hypothetical example shows that only by looking at constitutional prerogatives of central and local governments can be misleading in defining/measuring decentralization.

Due to its complicated nature, the debate over what are the characteristics of a decentralized state has been ample, although lately, there seems to be a consensus over the fact that decentralization can be seen as a cumulus of mainly three factors (Rodden, 2004; Schneider, 2003):

The regional governments can raise taxes and revenues independently from the central government. This is referred to as fiscal decentralization and proposed measures for it are the ratio between regional and general government revenues, the ratio between regional and general government expenditures or the share of all the tax revenues collected by the regional government. Of course, here certain points can be raised with respect to any of these measures; the first and second measure will fail in the case where the budget of regions is financed through transfers and grants by the central government, while the third one will fail in the case where the regional/local authorities are mere tax collectors for the central government, which is the one that decides the tax rate and base (Rodden, 2004).

Some policy areas are the realm of regional authorities. It is referred as administrative or policy decentralization. This characteristic can only be measured by making a case-by-case analysis of constitutional prerogatives of different countries. The tediousness of this task did not stop political scientists; for instance, Henderson (2000) using data for 1960-1995 and using a scale of 0-4 managed to code this characteristic by looking at whether educational and infrastructure policies are the sole prerogatives of regional government, central governments or shared between the two. The high cost in time required to compute an index of such kind discouraged many; furthermore, the data in this regard are not widespread.

The presence of regional elections as a form of interest aggregation and representation at local level, which can also signal the accountability of local offices in the face of the citizens. This characteristic is referred to as political decentralization and proposed ways to measure it are 
instrumental variables indicating the presence or absence of such elections, both at municipal/local level and regional level (Schneider, 2003). Of course, here certain points can be raised with respect to the reliability of such information: do the central government imposes a predefined list of candidates at local level (power of agenda setting) or is the other way around, in the sense that the local political leaders/electors have a very strong word in selecting the candidate that should run for a central government position, as is the case in Germany, Australia and US (Rodden, 2004)?

As it can be noted from the discussion above, none of these proposed measures are quite perfect, but while criticized by many, the most used for decentralization is the fiscal one (Clark et al., 2013); as demonstrated by Rodden, (2004) this measure also has the highest correlation and significance coefficients in a pairwise matrix with all the other proposed measures. Furthermore, as opposed to the others, it is quite convenient due to the fact that cross-section data for it are widely publicized by relevant international organizations such as IMF (Government Finance Statistics) or Eurostat, while in the case of other measures, the researcher need to go on a case-bycase study of their own.

Another point related to decentralization and survivability of cabinets that we have to consider is the role played by the regional parties in the national cabinets. The survival of a certain cabinet depends on many factors, but the main one, as stated also in the next section, cumulates the overall environment conditions in the national legislature. There, the power of parties and factions is relative and it should come as nothing new or surprising the fact that "small and resolute blocs" - as the regional parties in national parliaments usually are - can have an impressive amount of relative power, especially if they are to vote in a mass of indifferent population (Penrose, 1946). Such blocks are referred to as "critical voters", as they can shift the result of an election easily, even if they have relative small number of representatives; they can also be considered as having conditional veto over policy in the case when no single party detains the majority (Heller, 2002). In such a context our attention should be drawn by the role played by regional parties in the overall political stability of states. By stability we refer to a low cabinets turnover.

\section{The origins and proliferation of regional parties}

For clarification purposes, we would like to refer to regional parties as the political parties that have their electoral base in just one region of a country. While it is true that some regional parties are more "regionalist" (i.e. they campaign for more autonomy in their region) than others, 
these are just a subset. Thus, for the purposes of this paper, when talking about regional parties, we refer to the broader sense of the concept. The traditional explanation regarding the origins of the regional parties is, just as in the case of national parties, related to the concept of social cleavages (Lipset \& Rokkan, 1967). Regional parties tend to form where there are regional interests that are not properly represented on the stage of state politics, even if we talk about differences in terms of culture, ethnicity and language or differences in economic development; over- and under-development are causes very much cited in the literature (Brancati, 2008). A strong emphasis should be given to economic causes: regional parties tend to appear and win votes in regions where the voters are well aware that "outside vs. remain" calculation favors the former; i.e. the bigger the GDP of the region and the better the prospects of independence for it, the greater the share of votes for regional parties which will bargain for more autonomy and better payoffs at the central level, independently of whether to voters care or not for their regionalist identity (Fearon \& Van Houten, 2002).

In the same line of though with respect to social cleavages, Grossman and Lewis (2014) by focusing on the case of Uganda, found proof the fact that new administrative territorial units and powerful local leaders and factions emerge especially where citizens consider themselves marginalized with respect to the core of the country/region, but only if there is confluence of local interests and national ones - the gain of national governments is mainly of electoral nature, thing emphasized also by other authors (Resnick, 2017); in this kind of situations the local leaders manage to get a hold on power of a new region (these new regions usually secede from the bigger, more heterogeneous ones) and local citizens get a closer position to the policy-making locus, while the national governments, besides the better electoral prospects in this newly formed district, will get more influence (interestingly, thus a process of "recentralization" occurs) due to the fact that the new region is smaller and more homogenous, things that affect the citizens capacity for collective action. This will also result in a subsequent lower level and quality of public goods and services they receive (Grossman \& Lewis, 2014).

Although this explanation of social cleavages is widely accepted by many political scientists, it does not encompass all the cases: as Brancati (2008) puts it, there are countries where strong cleavages exists without a very powerful regional representation, while in others the relative 
"uniformity" of the country is paired with strong regional parties ${ }^{1}$. The aforementioned author comes thus with a complementary explanation: the institutional framework of the country, i.e. the existence of political decentralization (understood as "a division of political authority among multiple levels of government in which each level is democratically elected and has independent decision-making power over at least one issue area") also influences the appearance of regional parties. Employing a statistical analysis with data for 37 democracies from 1945 till 2002 and controlling for relevant variables (such as the existence of strong regional cleavages, the fiscal decentralization, presidentialism, electoral representation, etc.) she manages to confirm her hypothesis (Brancati, 2008).

A very interesting case of regional parties' appearance and proliferation, different from what was discussed before is that of India, where in less than a decade, the aggregate vote share of such parties augmented from 26 percent (1991) to 46 percent (1999), while their number in the lower house of the Parliament increased from 19 (1991) to 35 (1999). This startling sudden increase of power of regional parties is explained by the fact that in 1989, as opposed to the previous period in the political history of India when cabinets were single party majorities, a coalition government formed; due to this, the political calculations also changed - if up until then the high-profile politician preferred positions in large nation-wide political parties due to the highest probability of obtaining payoffs related to being in office, with the advent of the coalition cabinets, the payoffs of being/forming regional parties equalized with those of being in a large one because the regional parties gained pivotal roles in cabinet formation. Thus, many high-profile politicians preferred to create or adhere to regional parties instead of competing for positions inside the large national-wide parties (Ziegfeld, 2012).

\section{The interplay of regional with national parties' interests and effects of regionalization}

What are the effects of regionalization of political power? Does the existence of regional parties have any effect on the national political landscape? As argued by Heller (2002), which

\footnotetext{
${ }^{1}$ Among the examples that fall in the first category (powerful regional cleavages, but very weak regional representation) (Brancati, 2008) enumerates Romania and Indonesia, while for the second category gives the example of former Czechoslovakia, even though these examples are very debatable; for instance, the Democratic Alliance of Hungarians Party in Romania has a very concentrated electorate in 3 counties and has had a strong representation in the Bucharest Parliament ever since 1990. Also, one should not forget that for most of its history, Czechoslovakia was a communist state with a dictatorial rule and should not be considered a representative democracy.
} 
focused its study on the case of Spanish political landscape between 1993 and 2000, regional parties compete for votes with national-wide parties in specific regions, but also tend to collaborate with them in the national parliaments by trading policy for authority in the sense that they help the national parties get the policies they want passed in return for transferring policy making authority to regional level.

The same author also offers an answer to the question of why the national parties collaborate or trade favors with the regional ones - employing a tow dimensional political space (one dimension being the left-right divide, while the second autonomy-centralization divide), it can easily be seen that either of the two represented national parties prefer to collaborate with the regional party in order to change the status-quo instead of collaborating with one another to maintain it, due to the closeness of the new status-quo to their preferred positions. As it can be noted from Figure 1, the status-quo lies at the intersection of second indifference contours of the two national parties (Nat1 and Nat2). As each party will want to move the status-quo to a position closer to their initial point, they both see an opportunity in collaborating with the regional party (Reg), knowing very well that such collaboration will sacrifice central government's influence in that respective region. The new status-quo policy point can lie at the intersection of the first (closer, more preferred) indifference contour of the regional party with either Nat1 (PolicyP1) or Nat2 (Policy P2). Besides this argument, the big national parties tend not to enter into coalition with one another due to the fact that they should find an equilibrium position between their office seeking behavior (the parties seek to win as many portfolios positions as possible) and a long known law in coalition formation: Gamson's law - the coalition parties will divide their cabinets portfolios in accordance with their respective vote shares (Warwick \& Druckman, 2006). Thus, in order to find the optimal position, the formateurs need to stay in line with the minimum winning coalition rationale, i.e. ally with the smallest party possible in order to insure the majority. 


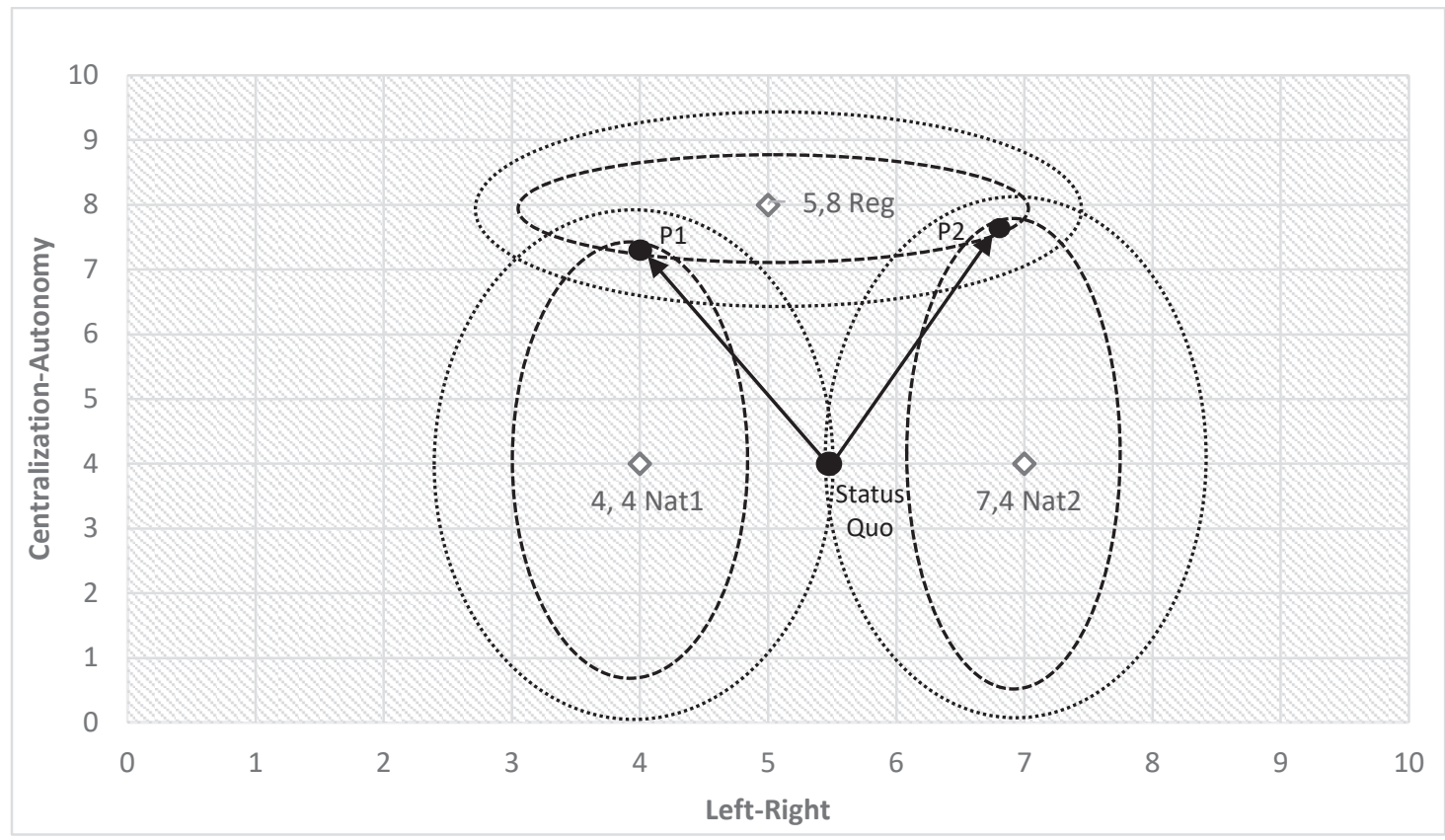

Figure 1 - A hypothetical two-dimensional political space (with left-right and autonomycentralization divides) with two national and a regional party. Source: own elaboration based on (Heller, 2002).

Two things should be noted though - the first one is the assumption that no large national party controls a majority in the parliament (otherwise, there wouldn't have been the need for alliances and trade-offs in the first place) and secondly, the regional party has a wider indifference contour with respect to left-right divide, as opposed to the national parties. This is possible due to the fact that the "mandate" of this kind of party is to represent the region in the resource allocation fight at the central level, not a policy preference in terms of ideology. Such position allows it to be more flexible in future political alliances and to enter into eventual coalition cabinets with more ease. Indeed, empirical evidence seems to suggest the validity of this theoretical assumption. For instance, in post-communist Romania and democratic Spain, the regional party form the Hungarian-populated region and regional parties from Basque Country and Catalonia respectively, have been in numerous occasions minor coalition partners (with or without portfolio position) in very ideologically different cabinets. Also, empirical evidences that can be found in the literature include the experiences of United Kingdom in the late 90s and that of Belgium in the late 70s (Heller, 2002). 
Some other empirical insights on the matter seem to suggest an improvement of democratic governance due to the rise of regional parties; for instance, Sadanandan (2012) brought evidence that in India, since the early 1990s the central usurpation of the power of regional governments via invoking article 356 of the Constitution was brought to a minimum since the independence due to the regional parties entering in opportunistic alliances with big national parties; the formers effectively act as veto players against the decisions of the latter in invoking the above mentioned article. In addition, it also brought a rise in institutional safeguards against the arbitrary takeovers of power by the central government.

At the same time, bilateral cooperation between regional governments seem to be more symbolic, at least in the case of Spain; ever since the adoption of Statute of Autonomies in the late 70s, the Southern European country have known a period of difficult horizontal coordination between its autonomous communities, thing that can be explained by the lack of congruence of regional parties interests, due to the fact that in these regions, non-state-wide parties usually come to power (Aja \& Colino, 2014). This discovery should come as no surprise; it is well known that if federalization is done through decentralization (as in the case of Spain and Belgium, for instance, - also known as "holding together federalism"), the electoral strategy of the parties is to focus on regional interests and regional disparities, while if it is done through the centralization of power (i.e. the regions agree to cede sovereignty in order to pool together resources for improved future outcomes (as in the case of the US, Australia, European Union - also known as "coming together federalism") the electoral strategy of the parties is to concentrate on common interests and common bonds (Brzinski, 1999; Riker, 1964).

With respect to the income inequality among regions, a relatively recent study with panel data from OECD countries that spanned over the period 1980-2007, seem to suggest that the dissimilarities in wealth at national level between regions explain the electoral success of regional parties and that the reverse causality is not present; i.e. the authors demonstrate that the presence and influence of regional parties do not positively affect income inequalities among regions, but vice versa (Kyriacou \& Morral-Palacin, 2015).

As stated already in the introduction, to our knowledge, only one work was concerned with the nexus between decentralization and political instability at the European level (Brancati, 2005). Although a very well done original analysis (with original data above all), we have a few points to raise. 
The first one is that the paper is only concerned with the destabilizing effect of the regional parties that are already represented in government and not with the overall effect of regional parties present in the national legislature. We believe that this is wrongly put due to the fact that many of the regional parties, and small parties in general, give support for a cabinet without occupying cabinet positions (the so-called "confidence and supply agreement") ${ }^{2}$ - thus cabinet survivability might depend on these parties without an a priori formal political coalition. Hereby, we will be more inclusive and consider the overall effect of regional parties on the cabinet durability, either if they are or not rewarded with portfolios. Thus, we can affirm that the originality of our work stems from this more encompassing and inclusive analysis.

Secondly, we believe that two of the control variables included in the model could have been considered in a better way; the first that we refer to is decentralization; in the above mentioned study this variable was a dichotomous indicating the existence or absence of at least one issue/policy where sub-national governments have decision-making powers. As explained above, this measure refers strictly to political decentralization and sometimes in the literature the existence of it is considered a necessary and sufficient condition for federalism (Clark et al., 2013). We believe is better to include fiscal decentralization as a ratio between regional and general government expenses (a continuum scale being a more accurate depiction of variability in data), than dichotomous dummy for the presence or absence of it. Also, by including this variable we also control for the effect that fiscal decentralization has on political stability in the sense that some regional parties and factions might not agree with the budget draft proposed by the government and due to this critical impasse could force a cabinet resignation. The second control variable that could be better coded is first democratic government; by including this variable, Brancati (2005) wanted to control for the existence of unstable first cabinets in young democracies; but we believe that by making a difference between the first and the subsequent cabinets in a young democracy does not make sense as there are no warranties of the fact that the second (or even the third or fourth, etc.) democratic government will be more stable than the first one. We believe that a more appropriate variable would have been a dichotomous dummy accounting for the status of transition democracy. Due to the fact that our study employs data for 2007-2017 in EU we will not include

\footnotetext{
2 Cases like this are very common in Spain, Romania and United Kingdom, for instance.
} 
this variable (or better yet, this constant) in our model due to the absence of such transitional democracies.

We also preferred to add some control variables that are either suggested by the literature and omitted in Brancati (2005), either more appropriate for the current European political landscape. This points that we raised should not be regarded as critics, but as ways to prove the robustness of this finding.

\section{Expected time in office - what matters and how to compute it?}

The question in order now should be: based on what is every cabinet judging their durability? As stated by Laver (2003), durability is a theoretical (latent) concept referring to the expected survivability of the cabinet and should be differentiated from duration, an empirical (observable) concept, which is the actual survived time in office.

Drawing from the book-length analysis made by Warwick in the early 90s, we can identify two schools of thought that entered in this debate (1995). The first one, with representative authors such as Taylor, Herman, Laver, Dodd and Strøm, which preferred to use an attributes analysis, i.e. independent variables that were statistically related to government durations, argued that the survival in power is determined by to what degree and by how many of the following conditions can be met: majority in parliament, minimum winning coalition (or single party majority), compactness of the ideology, low fragmentation index of the political system (otherwise identified as the complexity of the bargaining system). In turn, the other approach was based on what is called event analysis (or survival analysis) - starting from the basic assumption that the governments exist in a world of "critical events" (such as scandals, international conflicts, economic crises, etc.), each of which poses a threat to their existence, political scientist such as Browne, Frendreis and Cioffi-Revilla, argued that this so-called hazard rate (the potentiality of termination at certain points in time), was not a function of the attributes, but that of probabilities of such events happening - these authors demonstrated that the pattern observed for government terminations resembles a Poisson distribution (Laver, 2003; Warwick, 1995).

The debate reached an end in the mid 90's when hybrid models of cabinet duration, that is, including both attributes and critical events, were developed - the attributes were considered as the prime factors in determining the stochastic process of critical events, but also vice versa (the critical events could shape attributes of the political landscape). One of the pioneering works in 
this sense is that of Lupia and Strøm (1995) which reached the conclusion that stochasticallydetermined external events can deeply affect the outcome of the dynamics coalition bargaining, but not wholly determine them. The effect of these critical events will depend also on the context in which the parties of the coalition find themselves. This conclusion was reaffirmed in a latter paper by Diermeier and Stevenson (1999) that proved, among others, that hazard rates behave differently when analyzing government replacements, i.e. dismissals (in which case is represented by a flat line) and when analyzing government dissolution, i.e. a government ending in early elections (in which case the hazard rate is a line that gets steeper as the time in office passes for the cabinet).

Further works in this area had been conducted by Merlo (1997) who estimates a structural model of government formation and bargaining in postwar Italy (thus having the disadvantage of being a custom-made model, not applicable to all contexts), by Diermeier, Eraslan and Merlo (2003) which taking from the work of previously cited paper, managed to construct a government formation and duration model which highlights the importance of constitutional features such as constructive no confidence-vote, no investiture vote and fixed inter-election periods for the formation and duration of cabinets, and by Laver (2003), which makes an excellent up-to-date review of the methodology and of the literature, indicating the missing pieces from each approach and showing points for future improvement.

Another work that is worth mentioning is that of Chiba, Martin and Stevenson (2015) because it brought to attention and solved (through a copula approach) a long-lasting problem in the literature: the issue of selection bias; because government formation and duration are said to be dependent and were commonly estimated, the sample of observed governments analyzed in studies of government survival may be non-randomly selected from the population of potential governments. When trying to determine the durability of a government, we can base out estimation on certain features as stated above, but we neglected the fact that the governments that we chose as researchers, were already preselected through political bargaining when the coalition formed and the criteria used by politicians might or might not have coincided with the ones we considered important for formation and duration.

One thing that is worth mentioning and that might seem surprising is that even though is common sense among scholars assuming the high government turnover or short duration is intrinsically bad for democracy and economy broadly defined, there are only a handful of articles 
(no more than 3 to our knowledge) in the political science literature that put government durability "on the right side of the equation", i.e. as an independent variable and that found robust relationships (Fortunato \& Loftis, 2018). These are Harmel and Robertson (1986) which determines that high government turnovers (frequent government changes) negatively influence the overall satisfaction with democratic government, Huber (1998) which proved that short-run increases in portfolio volatility present problems for government decision-makers, but not in the long run, and Fortunato and Loftis (2018) which proved that instability positively affects public deficit and debt level.

\section{Research design and methodology}

As suggested in the literature, we set forth form the hypothesis that decentralization with its both dimensions, fiscal and political, negatively impacts the cabinet stability. In theory, the greater the power of sub-national actors (executives and regional parties in national parliament) with respect to national governments, the higher the cabinet turnover.

We have several reasons to believe that this link exists, as either Brancati (2005) pointed out either as the literature on the role of regional parties pointed out. The small regional parties may withdraw at any time their support for governing parties if their autonomy demands are not met (a highly probable scenario as these regional parties are very resolute, their demands are hard to meet by the nation-wide parties - it would mean relinquishing decision-making power at subnational level, thus a loss of influence). Another explanation for this link is that the regional parties could act as pivotal actors (due to their high relative power and very flexible voting behavior on the left-right divide) in determining the policies and cabinets even if they detain or not portfolio positions. The variables considered, replicating the models of many political science papers concerned with cabinet durability, are:

1. Days in office of each cabinet - dependent variable (Casal Bértoa, 2019; source: Döring \& Manow, 2019).

2. Dummy for caretaker government (Casal Bértoa, 2019; source: Döring \& Manow, 2019).

3. The numerical status of the government in the parliament; we considered the seats share as an indicator of majority/minority of the government because by considering only the polling results at elections could have been misleading; big parties are usually rewarded and small parties are punished when transforming votes into legislature seats. If in 
minority, 0, if in majority 1 (source: Casal Bértoa, 2019; European Consortium for Political Research, 2019).

4. Ruling number of parties (source: Casal Bértoa, 2019; European Consortium for Political Research, 2019).

5. The range between the most distant positions among the parties forming the government. Up until our work, these distances were computed using the left-right ideological distance (which we also include). But, in the contemporary European landscape (at least since the Great Recession of 2008), this left-right divide will give nonrepresentative results; that is why, we introduced a new method and a new dimension. We took into account, besides the classical left-right dimension, also the pro vs. contra European integration perspective of the parties. Using these two dimensions, we computed a matrix of Euclidean distances between all the parties in the countries of the EU28, and we choose the most distant positons in a coalition. The formula is the following:

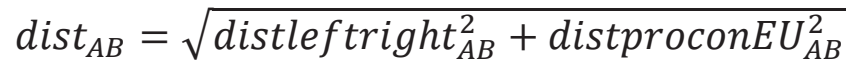

where $\operatorname{dist}_{A B}$ is the Euclidean distance between the hypothetical parties $\mathrm{A}$ and $\mathrm{B}$, distleftright $_{A B}$ is the left-right ideological distance between the same parties, and distproconE $U_{A B}$ is the distance between their views on European Union. Of course, the assumption here was that the more distant the governing coalition members, the sooner the coalition it will break (Döring \& Manow, 2019; source: own computations with data from Volkens et al., 2018).

6. The proportion of parties from current government that were part of the previous government (source: Casal Bértoa, 2019) - assumption: the higher the proportion, the lower the costs of the governing parties to break to current coalition, because they know it is a high probability of their return in power. Note: the independent portfolio holders in each cabinet were not considered, as theoretically they do not act as a political party per se and they are not represented as a group in the next government. 
7. The complexity of the bargaining system measured as the effective number of political parties at the parliamentary or legislative level (source: Gallagher, 2019), under the assumption that a complex bargaining system will create cabinets more prone to the shocks, thus lowering their survivability. The formula used for computing the effective number of parties is as follows (Laakso \& Taagepera, 1979):

$$
N=\frac{1}{V_{1}^{2}+V_{2}^{2}+\cdots V_{n}^{2}}
$$

where $N$ is the effective number of parties, and $V^{2}$ with subscript is the squared vote share of party $\mathrm{i}$ (in decimals).

8. Fiscal decentralization index, computed as the ratio between regional plus local expenses to general government expenses (source: Eurostat) - under the assumption that the more decentralized a state, the more unstable are its cabinets (when sub-national actors are unhappy with redistribution of fiscal resources in their region, they voice their concerns in national parliaments against the incumbent government).

9. An index for political decentralization - the seats share of regional parties inside the national legislatures.

In order to assess the effect of each variable on the times in office for each government, we employed both semi-parametric/proportional (Cox) and parametric (Weibull) models of survival analysis. The proportional hazard rates model was employed in Brancati (2005), thus giving us the chance to check for the robustness of the findings, while the Weibull parametric model is more widespread in studies concerned with cabinet survivability (Chiba et al., 2015; Diermeier \& Stevenson, 1999; Fortunato \& Loftis, 2018). In fact, one of the pioneering studies in this field (Warwick, 1995) already recommended the use of graphical analysis (of both survival function and baseline hazard rates) in order to determine which model to be employed; as explained in the paragraph dedicated to results and discussions, graphical analysis suggested the use of a parametric Weibull model. 
The difference between the two is that the first one (Cox) does not assume any baseline hazard function, while the second one assumes, in our case, an increasing baseline function (Kleinbaum \& Klein, 2012). One thing that is worth mentioning about the hazard rates; given that the formula for hazard function is:

$$
h(t)=\lim _{\Delta t \rightarrow 0} \frac{P(t \leq T<t+\Delta t \mid T>t)}{\Delta t}
$$

where $h(t)$ is the hazard rate at time $t, \lim _{\Delta t \rightarrow 0}$ is the value of the function as $\Delta t$ (the time unit) approaches $0 ; P(t \leq T<t+\Delta t \mid T>t)$ is the conditional probability of individual fails in the interval between $t+\Delta t$, given that the subject survived by then. Hazard rates should not be interpreted as probabilities, but rather as probability per time (Kleinbaum \& Klein, 2012).

Survival analysis requires a special treatment of data and cannot be substituted by regular linear regression mainly due to two reasons: the first one is that due to the fact that the dependent variable is always a time unit, its estimated value cannot be negative (in a linear regression case it can be) and secondly, the data from the survey can be censured and this is a special case of missing data, that offers important information on the observations (Kleinbaum \& Klein, 2012). In our case, as the sample we extracted finishes in 2017, the cabinets still in office on January 1st 2018, were considered censored observations.

\section{Results and discussions}

With data for more than 190 cabinets from EU 28, we will start this section by exposing some descriptive statistics, presented in Table 1 and by presenting the correlation matrix in Table 2.

\begin{tabular}{|c|c|c|c|c|c|}
\hline Variable & Obs. & Mean & Std. Dev. & Min. & Max. \\
\hline Duration & 192 & 656.417 & 499.591 & 7 & 1885 \\
\hline Failures & 192 & .922 & .269 & 0 & 1 \\
\hline Caretaker & 192 & .13 & .337 & 0 & 1 \\
\hline Government status & 192 & .656 & .476 & 0 & 1 \\
\hline Parties in cabinet & 192 & 2.599 & 1.258 & 1 & 7 \\
\hline Returnability & 192 & 53.481 & 38.438 & 0 & 100 \\
\hline Euclidean distance & 190 & 18.424 & 18.413 & 0 & 87.878 \\
\hline Left-right distance & 192 & 2.077 & 1.689 & 0 & 5.905 \\
\hline Fiscal decentralization & 192 & .335 & .145 & 0 & .715 \\
\hline Regional parties share & 190 & .03 & .057 & 0 & .274 \\
\hline $\begin{array}{l}\text { Effective number of } \\
\text { parties }\end{array}$ & 192 & 4.091 & 1.507 & 1.97 & 8.42 \\
\hline
\end{tabular}


Table 1 -Descriptive statistics for the variables considered in the model. Source: own computation

The correlation between cabinet duration and fiscal and political decentralization measures are truly negative as predicted by the theory, but the relationship seems to be very weak with coefficients of approximately -0.1 and -0.14 respectively.

\begin{tabular}{|c|c|c|c|c|c|c|c|c|c|c|}
\hline Variables & $(1)$ & $(2)$ & (3) & (4) & (5) & $(6)$ & $(7)$ & $(8)$ & $(9)$ & $(10)$ \\
\hline (1) Duration & 1.000 & & & & & & & & & \\
\hline (2) Caretaker & - & 1.000 & & & & & & & & \\
\hline (3) Government status & 0.266 & -0.286 & 1.000 & & & & & & & \\
\hline (4) Parties in cabinet & 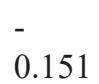 & -0.132 & 0.299 & $\begin{array}{l}1.00 \\
0\end{array}$ & & & & & & \\
\hline (5) Returnability & $\begin{array}{l}- \\
0.162\end{array}$ & -0.004 & 0.097 & $\begin{array}{l}0.01 \\
3\end{array}$ & $\begin{array}{l}1.00 \\
0\end{array}$ & & & & & \\
\hline (6) Euclidean distance & $\begin{array}{l}- \\
0.122\end{array}$ & -0.044 & 0.237 & $\begin{array}{l}0.55 \\
1\end{array}$ & $\begin{array}{l}0.09 \\
2\end{array}$ & 1.000 & & & & \\
\hline (7) Left-right distance & 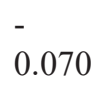 & -0.133 & 0.402 & $\begin{array}{l}0.66 \\
9\end{array}$ & $\begin{array}{l}0.03 \\
5\end{array}$ & 0.557 & 1.000 & & & \\
\hline (8) Fiscal decentralization & 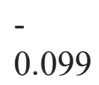 & 0.116 & 0.061 & $\begin{array}{l}0.29 \\
0\end{array}$ & $\begin{array}{l}0.04 \\
1\end{array}$ & 0.219 & 0.069 & 1.000 & & \\
\hline (9) Regional parties share & $\begin{array}{l}- \\
0.147\end{array}$ & 0.291 & -0.164 & $\begin{array}{l}0.10 \\
9\end{array}$ & $\begin{array}{l}0.01 \\
1\end{array}$ & 0.108 & 0.006 & 0.150 & 1.000 & \\
\hline (10) Effective number of parties & 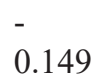 & 0.153 & 0.006 & $\begin{array}{l}0.51 \\
2\end{array}$ & $\begin{array}{l}0.21 \\
4\end{array}$ & 0.485 & 0.348 & 0.230 & 0.298 & 1.000 \\
\hline
\end{tabular}

Table 2 - Correlation matrix. Source: own computation

As the graphs below show, as the time passes by, the probability of survival (Y axis) diminishes (Figure 5). In Figure 6, we have the represented the hazard rate function, i.e. the instantaneous potentiality at each time unit for the critical event (in our case, the fall of cabinet) to happen, given that the subject survived by then. Both graphical representations are in accordance with the structure of our data and with our theoretical expectations, i.e. it suggests the use of a Weibull model, due to the continually decreasing survival estimate function (confirmed also by the Akaike Information Criterion contrast between the two models).
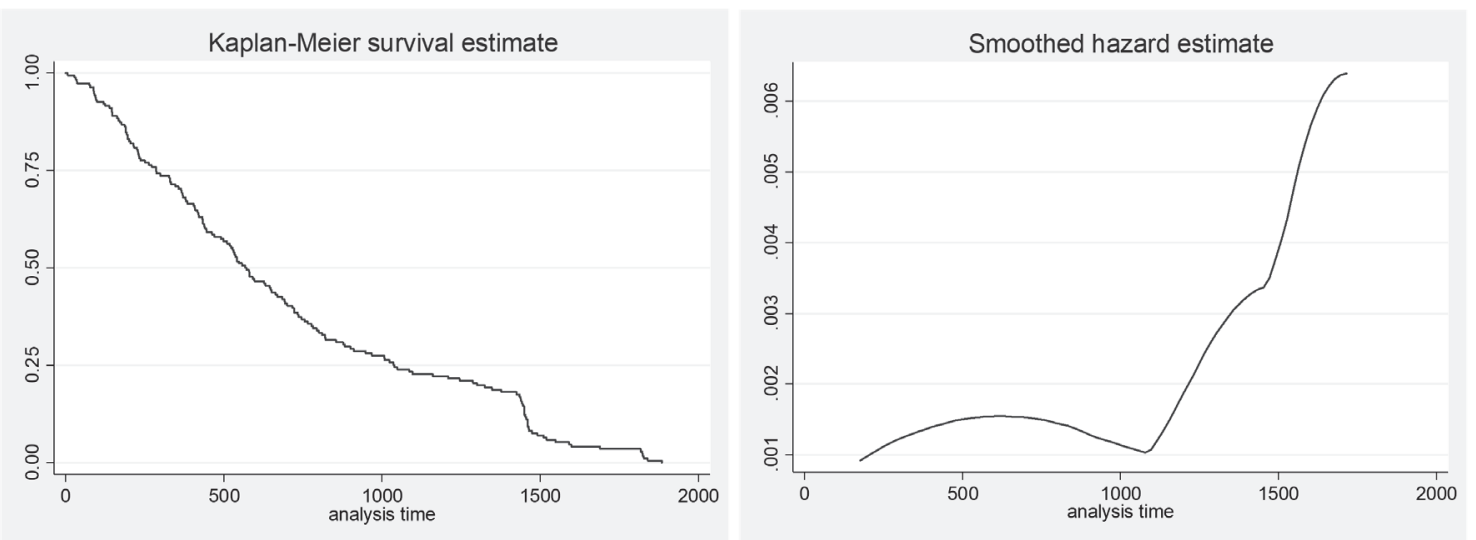

Figure 1 (left) - Graphical representation of the survival function of cabinets in our sample. Source: own elaboration 
Figure 2 (right) - Graphical representation of hazard rates. Source: own elaboration

In Table 3, Table 4 and Table 5 we have represented the results for our estimations. As noted, none of the two decentralization measures considered for testing seem to present any significant effect over cabinet durability, even though they have the expected signs, in neither of the two competing models considered. With coefficients and hazard rates for fiscal decentralization with a p-value of close to 0.6 and for political decentralization with close to 0.8 cannot we reject the null hypothesis.

\begin{tabular}{|c|c|c|c|c|c|c|c|}
\hline Duration & Coef. & St.Err. & $\begin{array}{l}\text { t- } \\
\text { value }\end{array}$ & p-value & [95\% Conf. & Interval] & Sig \\
\hline Caretaker & 3.248 & 0.796 & 4.81 & 0.000 & 2.009 & 5.252 & $* * *$ \\
\hline Government status & 0.670 & 0.125 & -2.15 & 0.031 & 0.465 & 0.964 & $* *$ \\
\hline Parties in cabinet & 1.213 & 0.111 & 2.11 & 0.035 & 1.014 & 1.452 & $* *$ \\
\hline Returnability & 1.003 & 0.002 & 1.72 & 0.086 & 1.000 & 1.007 & $*$ \\
\hline Left-right distance & 1.028 & 0.066 & 0.43 & 0.666 & 0.907 & 1.166 & \\
\hline Effective number of parties & 0.896 & 0.064 & -1.55 & 0.122 & 0.779 & 1.030 & \\
\hline Fiscal decentralization & 1.355 & 0.749 & 0.55 & 0.582 & 0.459 & 4.001 & \\
\hline Regional parties share & 1.630 & 2.254 & 0.35 & 0.724 & 0.108 & 24.501 & \\
\hline Mean dependent var. & 654.595 & & ender & & 496.857 & & \\
\hline Number of obs. & 190.000 & & quare & & 36.135 & & \\
\hline Prob. $>$ chi 2 & 0.000 & & ke crit. & C) & 466.817 & & \\
\hline
\end{tabular}

$* * * \mathrm{p}<0.01, * * \mathrm{p}<0.05, * \mathrm{p}<0.1$

Table 3 - Results for the semi-parametric/proportional (Cox) survival analysis. Source: own computation

It is also worthy of mentioning the fact that both measures for maximum distances between ideological positions in cabinet (Euclidean and classical left-right) are also insignificant p-values of approximately 0.9 and 0.6 respectively (suggesting that during the period of the selected sample, 2007-2017, the ideological dimension seem to be insignificant, while other studies like those of Brancati (2005), Chiba et al. (2015) and Fortunato and Loftis (2018), employing samples from the postwar period to the beginning of the $21^{\text {st }}$ century, proved the opposite, i.e. the significance of the ideological dimension on cabinet durability) ${ }^{3}$. The effective number of political parties in parliament is significant, but at $10 \%$.

As opposed to a classic regression, the dependent variable considered in the model is in fact a combination of the information from two sources: the time and failure, i.e. the cabinet duration and cabinet replacement ( 1 the cabinet was replaced, 0 if the observation is right censured). Hazard rates above one indicate a government is more likely to collapse while hazard rates below one indicate a government is less likely to collapse.

The coefficients for hazard rates in this case have a different interpretation; if higher than 1 , subtract from the hazard ratios 1 and interpret the result in percentages. For instance, if the

\footnotetext{
${ }^{3}$ A quite interesting result that seems to be in line with the widespread popularity fall of the traditional left-right parties in Europe in recent times and that could be considered for further research.
} 
cabinet is a caretaker, its chances of survival drops with 570\% (i.e. $6.7-1=5.7)$ if the cabinet that holds majority in legislature ( 1 for Government status variable, 0 otherwise) has a positive effect on survival time, i.e., it increases the durability by close to $55 \%$, while an increase with one in the ruling number of parties (Parties in cabinet), determines a lowering of survival likelihood by $30 \%$. A counterintuitive effect (at least for the authors) was observed in the case of the complexity of the bargaining system (measured as the effective number of political parties) if the effective number of parties increases by 1 , the survival likelihood increases by $13 \%$; we suspect that this may be due to the fact that a higher number of parties in the legislature, even though represents a bigger pool of hypothetical political allies in the next cabinet formation, will also increase the costs associated with cabinet formation; thus once a government is formed in a complex legislature, it will want to maintain the status-quo so it won't incur further renegotiations costs.

\begin{tabular}{|c|c|c|c|c|c|c|c|}
\hline Duration & Coef. & St.Err. & $\mathrm{t}$-value & $\mathrm{p}$-value & [95\% Conf. & Interval] & Sig \\
\hline Caretaker & 6.769 & 1.865 & 6.94 & 0.000 & 3.945 & 11.616 & $* * *$ \\
\hline Government status & 0.559 & 0.106 & -3.07 & 0.002 & 0.385 & 0.810 & $* * *$ \\
\hline Parties in cabinet & 1.316 & 0.121 & 3.00 & 0.003 & 1.100 & 1.575 & $* * *$ \\
\hline Returnability & 1.005 & 0.002 & 2.54 & 0.011 & 1.001 & 1.009 & $* *$ \\
\hline Left-right distance & 1.030 & 0.066 & 0.46 & 0.644 & 0.908 & 1.169 & \\
\hline Effective number of parties & 0.870 & 0.065 & -1.85 & 0.064 & 0.751 & 1.008 & $*$ \\
\hline Fiscal decentralization & 1.298 & 0.713 & 0.48 & 0.634 & 0.443 & 3.809 & \\
\hline Regional parties share & 1.371 & 1.925 & 0.23 & 0.822 & 0.088 & 21.483 & \\
\hline Mean dependent var. & 654.595 & \multirow{3}{*}{\multicolumn{3}{|c|}{$\begin{array}{l}\text { SD dependent var. } \\
\text { Chi-square } \\
\text { Akaike crit. (AIC) }\end{array}$}} & 496.857 & & \\
\hline Number of obs. & 190.000 & & & & 68.482 & & \\
\hline Prob. $>$ chi2 & 0.000 & & & & 411.733 & & \\
\hline
\end{tabular}

*** $\mathrm{p}<0.01, * * \mathrm{p}<0.05, * \mathrm{p}<0.1$

Table 4 - Results for the Weibull parametric survival analysis with left-right distances considered. Source: own computation

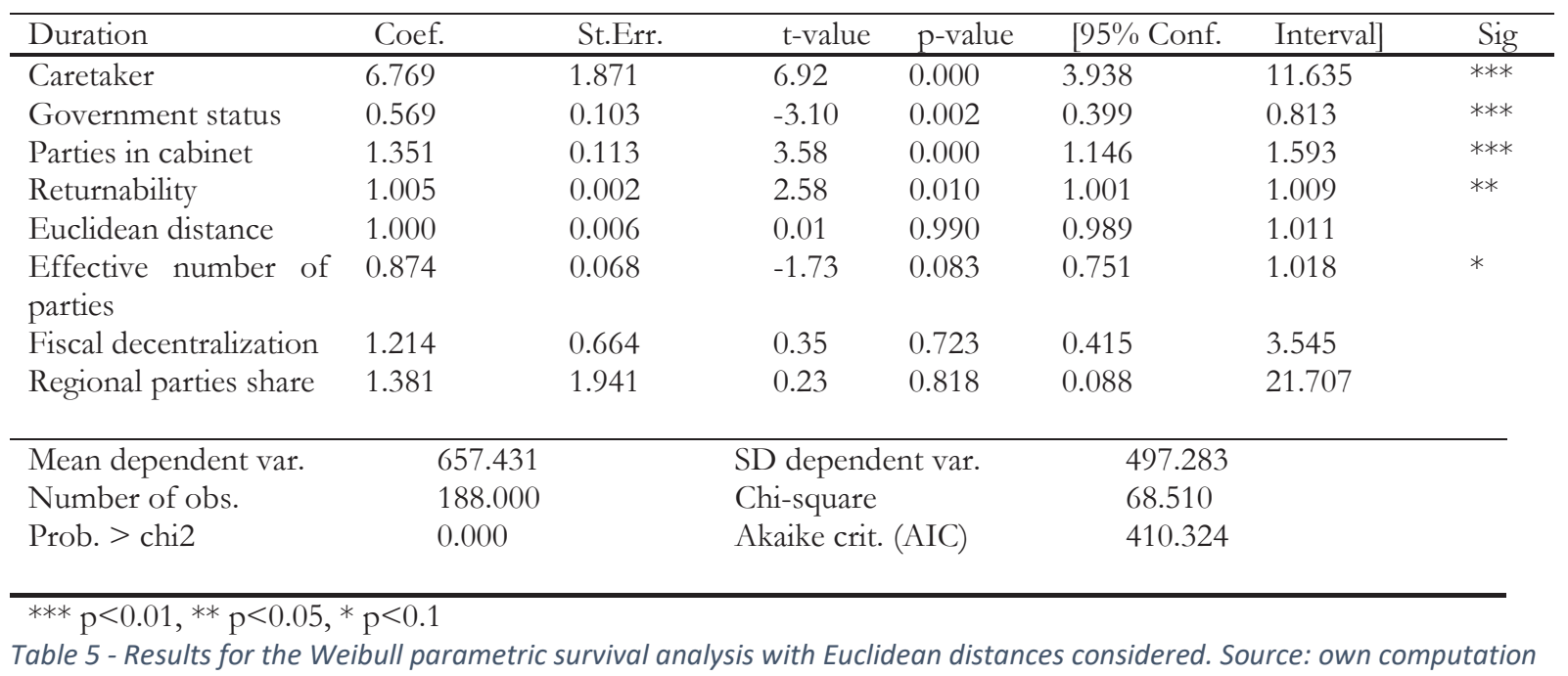




\section{Conclusions}

As indicated above, after controlling for all the relevant institutional and cabinet-specific factors, we determined that in the last decade's EU political landscape, the time horizon of each cabinet is not affected in any way by the fiscal or political decentralization of the country. This result comes against the previous findings, although this contradiction can be explained by some differences of methodological and research design order. Our study was more inclusive in considering the effect of political decentralization (as indicated by the power of regional parties in national legislatures) because it took into account also the supply and confidence agreements between these small parties and the big national ones, as opposed to the previously cited study that only took into account the effects of regional parties with portfolio positions. Thus, in order to reconcile the seemingly opposite findings, we could say that while in cabinet, the small regional parties can act as pivotal players and their behavior affects the political stability of the country in a negative sense, but while performing either their supply and confidence duties either their opposition roles, they do not affect it in any way.

Furthermore, we can say that, even though it wasn't its scope, this study also discovered some very puzzling relationships that were taken as granted before: the effect of the ideological dimension and that of the complexity of the bargaining system on cabinet durability. These findings might have to do with the very recent sample that we extracted; while most of the studies conducted in this area were sampling for longer periods of time (usually 1945-beginning of the $21^{\text {st }}$ century), our study was only focused only with the last decade's politics. These puzzling findings might suggest some structural changes in the European political landscape that worth further research.

\section{References}

1. Aja, E., \& Colino, C. (2014). Multilevel structures, coordination and partisan

2. politics in Spanish intergovernmental relations. Comparative European Politics, 12(4-5) doi:10.1057/cep.2014.9

3. Brancati, D. (2005). Pawns take queen: The destabilizing effects of regional parties in europe. Constitutional Political Economy, 16(2), 143-159. doi:10.1007/s10602-005-22337

4. Brancati, D. (2008). The origins and strengths of regional parties. British Journal of Political Science, 38(1), 135-159. Retrieved from http://www.jstor.org/stable/27568336

5. Brzinski, J. B. (1999). Changing forms of federalism and party electoral strategies: Belgium and the european union. Publius, 29(1), 45-70. doi:10.2307/3330919 
6. Casal Bértoa, F. (2019). Database on WHO GOVERNS in Europe and beyond. Retrieved from https://whogoverns.eu/

7. Chiba, D., Martin, L. W., \& Stevenson, R. T. (2015). A copula approach to the problem of selection bias in models of government survival. Political Analysis, 23(1), 42-58. doi:10.1093/pan/mpu013

8. Clark, W. R., Golder, M., \& Golder, S. N. (2013). Principles of comparative politics (2nd ed.). Thousand Oaks: CQ Press.

9. Diermeier, D., Eraslan, H., \& Merlo, A. (2003). A structural model of government formation. Econometrica, 71(1), 27-70. doi:10.1111/1468-0262.00389

10. Diermeier, D., \& Stevenson, R. T. (1999). Cabinet survival and competing risks. American Journal of Political Science, 43(4), 1051-1068. doi:10.2307/2991817

11. Döring, H., \& Manow, P. (2019). Parliaments and governments database (ParlGov): Information on parties, elections and cabinets in modern democracies.\&nbsp;

12. European Consortium for Political Research. (2019). European journal of political research political data yearbook.

13. Fearon, J. D., \& Van Houten, P. (2002). (2002). The politicization of cultural and economic difference. Paper presented at the Fifth Meeting of the Laboratory in Comparative Ethnic Processes. Stanford University, May,

14. Fortunato, D., \& Loftis, M. W. (2018). Cabinet durability and fiscal discipline. American Political Science Review, 112(4), 939-953. doi:10.1017/S0003055418000436

15. Gallagher, M. (2019). Election indices dataset. (). Retrieved from https://www.tcd.ie/Political_Science/people/michael_gallagher/ElSystems/Docts/Election Indices.pdf

16. Grossman, G., \& Lewis, J. I. (2014). Administrative unit proliferation. American Political Science Review, 108(1), 196-217. doi:10.1017/S0003055413000567

17. Harmel, R., \& Robertson, J. D. (1986). Government stability and regime support: A crossnational analysis. The Journal of Politics, 48(4), 1029-1040. doi:10.2307/2131011

18. Heller, W. B. (2002). Regional parties and national politics in Europe - Spain's estado de las autonomias, 1993 to 2000. Comparative Political Studies, 35(6), 657-685. doi:10.1177/0010414002035006002 
19. Henderson, J. V. (2000). The effects of urban concentration on economic growth. NBER Papers, (No. w7503)

20. Huber, J. D. (1998). How does cabinet instability affect political performance? portfolio volatility and health care cost containment in parliamentary democracies. The American Political Science Review, 92(3), 577-591. doi:10.2307/2585482

21. Kleinbaum, D. G., \& Klein, M. (2012). Survival analysis: A self-learning text. New York: Springer.

22. Kyriacou, A. P., \& Morral-Palacin, N. (2015). Regional inequalities and the electoral success of regional parties: Evidence from the OECD. Publius-the Journal of Federalism, 45(1), 3-23. doi:10.1093/publius/pju007

23. Laakso, M., \& Taagepera, R. (1979). "Effective" number of parties: A measure with application to west europe. Comparative Political Studies, 12(1), 3-27. doi:10.1177/001041407901200101

24. Laver, M. (2003). Government termination. Annual Review of Political Science, 6(1), 2340. doi:10.1146/annurev.polisci.6.121901.085530

25. Lipset, S. M., \& Rokkan, S. (1967). Party systems and voter alignments: Cross-national perspectives.\&nbsp;. New York: The Free Press.

26. Lupia, A., \& Strøm, K. (1995). Coalition termination and the strategic timing of parliamentary elections. The American Political Science Review, 89(3), 648-665. doi: $10.2307 / 2082980$

27. Merlo, A. (1997). Bargaining over governments in a stochastic environment. Journal of Political Economy, 105(1), 101-131. Retrieved from http://www.jstor.org/stable/2138873

28. Penrose, L. S. (1946). The elementary statistics of majority voting. Journal of the Royal Statistical Society, 109(1), 53-57. doi:10.2307/2981392

29. Resnick, D. (2017). Democracy, decentralization, and district proliferation: The case of Ghana doi://doi.org/10.1016/j.polgeo.2017.02.011

30. Riker, W. H. (1964). Federalism: Origin, operation, significance. Boston: Little, Brown.

31. Rodden, J. (2004). Comparative federalism and decentralization - on meaning and measurement. Comparative Politics, 36(4), +. doi:10.2307/4150172

32. Sadanandan, A. (2012). Bridling central tyranny in India. How regional parties restrain the federal government. Asian Survey, 52(2), 247-269. doi:10.1525/as.2012.52.2.247 
33. Schneider, A. (2003). Decentralization: Conceptualization and measurement. Studies in Comparative International Development, 38(3), 32-56. doi:10.1007/BF02686198

34. Volkens, A., Krause, W., Lehmann, P., Matthieß Theres, Merz, N., Regel, S. \& Weßels, B. (2018). The manifesto data collection. manifesto project (MRG/CMP/MARPOR). version 2018b. Retrieved from https://doi.org/10.25522/manifesto.mpds.2018b

35. Warwick, P. (1995). Government survival in parliamentary democracies. Cambridge: Cambridge University Press. doi:10.1017/CBO9780511528132 Retrieved from https://www.cambridge.org/core/books/government-survival-in-parliamentarydemocracies/3CCAD28F43FE08980CB0A0F491A05D23

36. Warwick, P., \& Druckman, J. N. (2006). The portfolio allocation paradox: An investigation into the nature of a very strong but puzzling relationship. European Journal of Political Research, 45(4), 635-665. doi:10.1111/j.1475-6765.2006.00632.x

37. Ziegfeld, A. (2012). Coalition government and party system change: Explaining the rise of regional political parties in India. Comparative Politics, 45(1), 69-87. Retrieved from http://www.jstor.org/stable/41714172.

\section{Appendix}

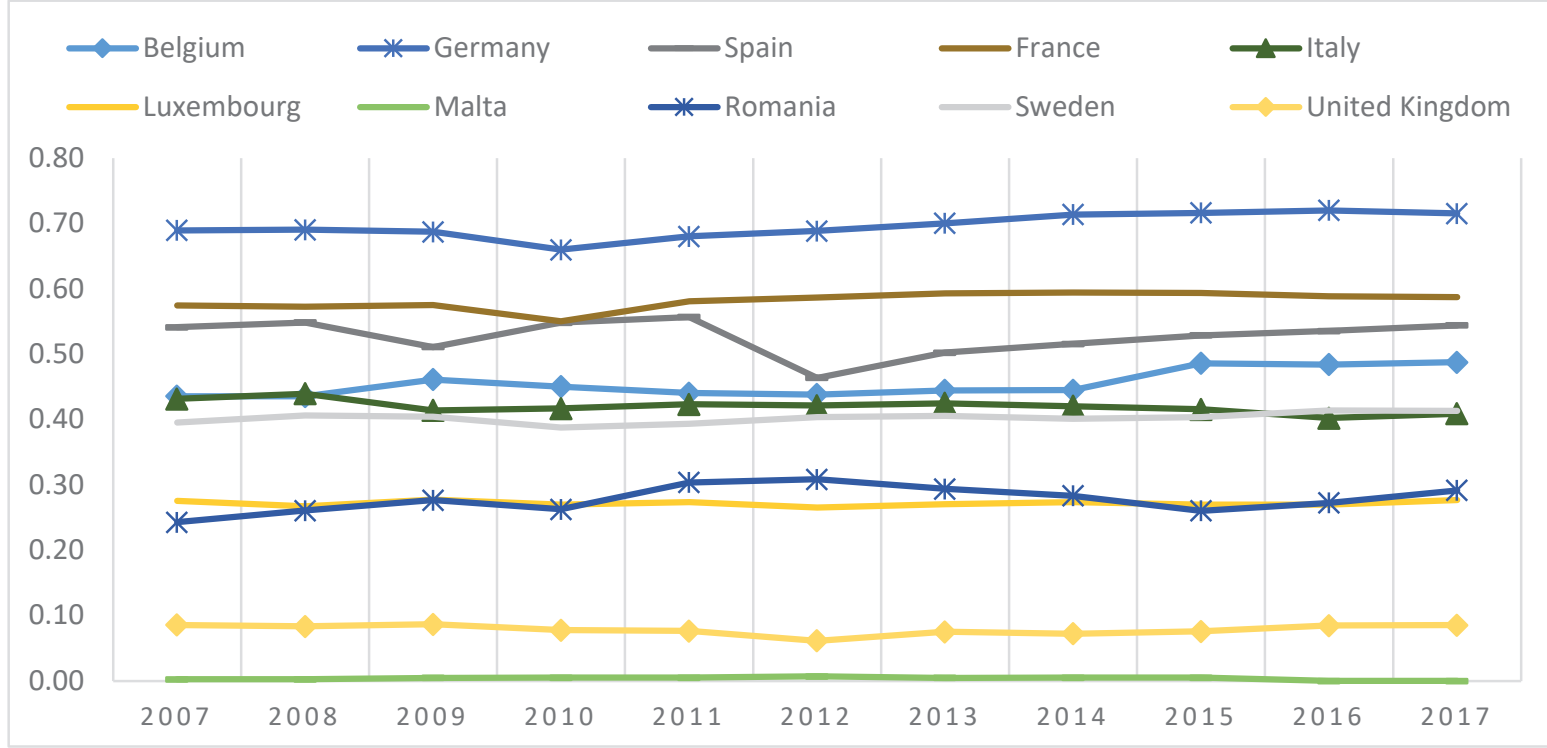

Figure 3 - Fiscal decentralization index for 10 EU countries 2007-2017. Source: own elaboration with data from Eurostat 


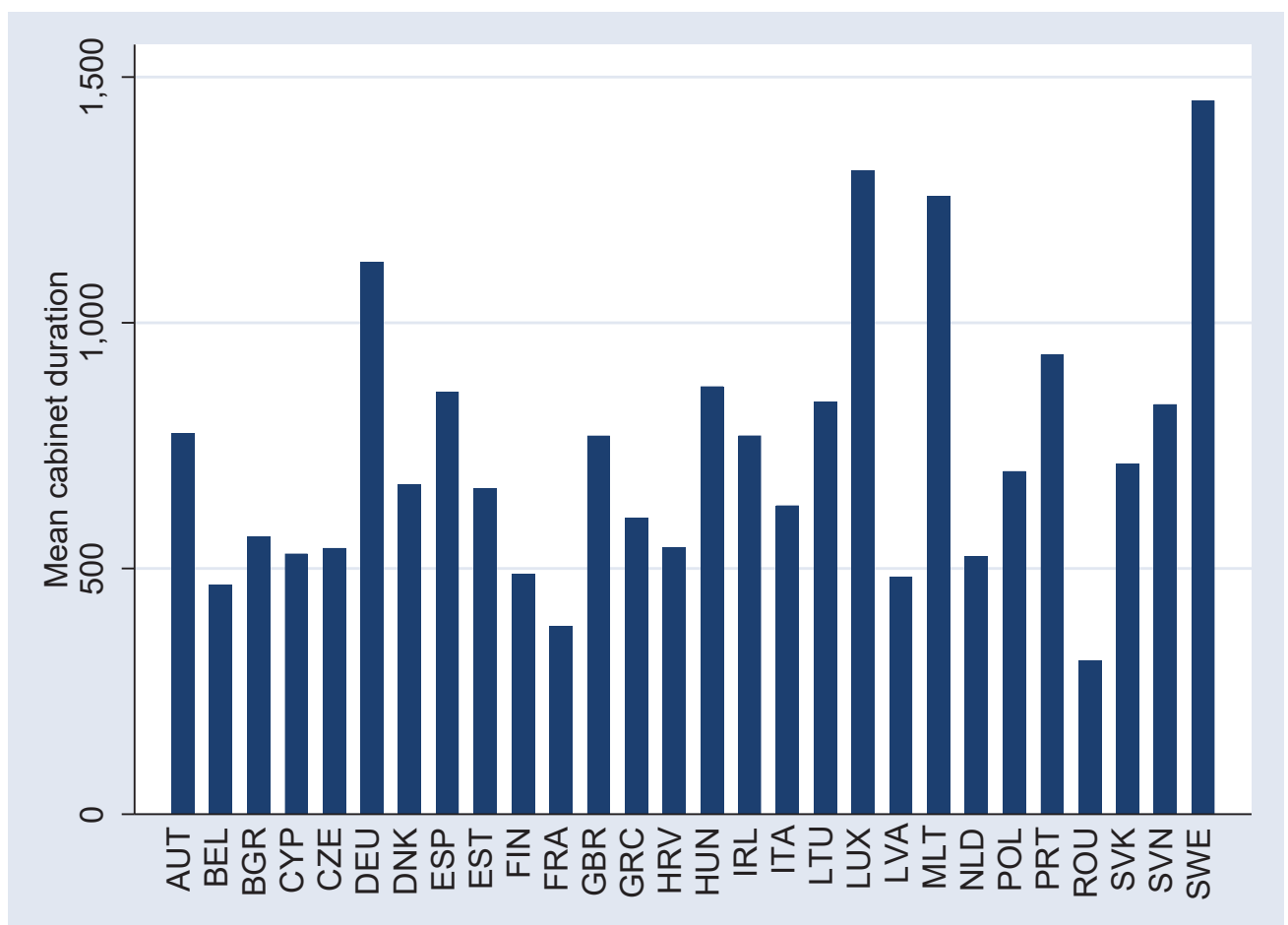

Figure 4 - Mean cabinet duration by country (EU28) 2007-2017. Source: own elaboration with data from ParlGov (Döring \& Manow, 2019) and Casal Bértoa (2019)

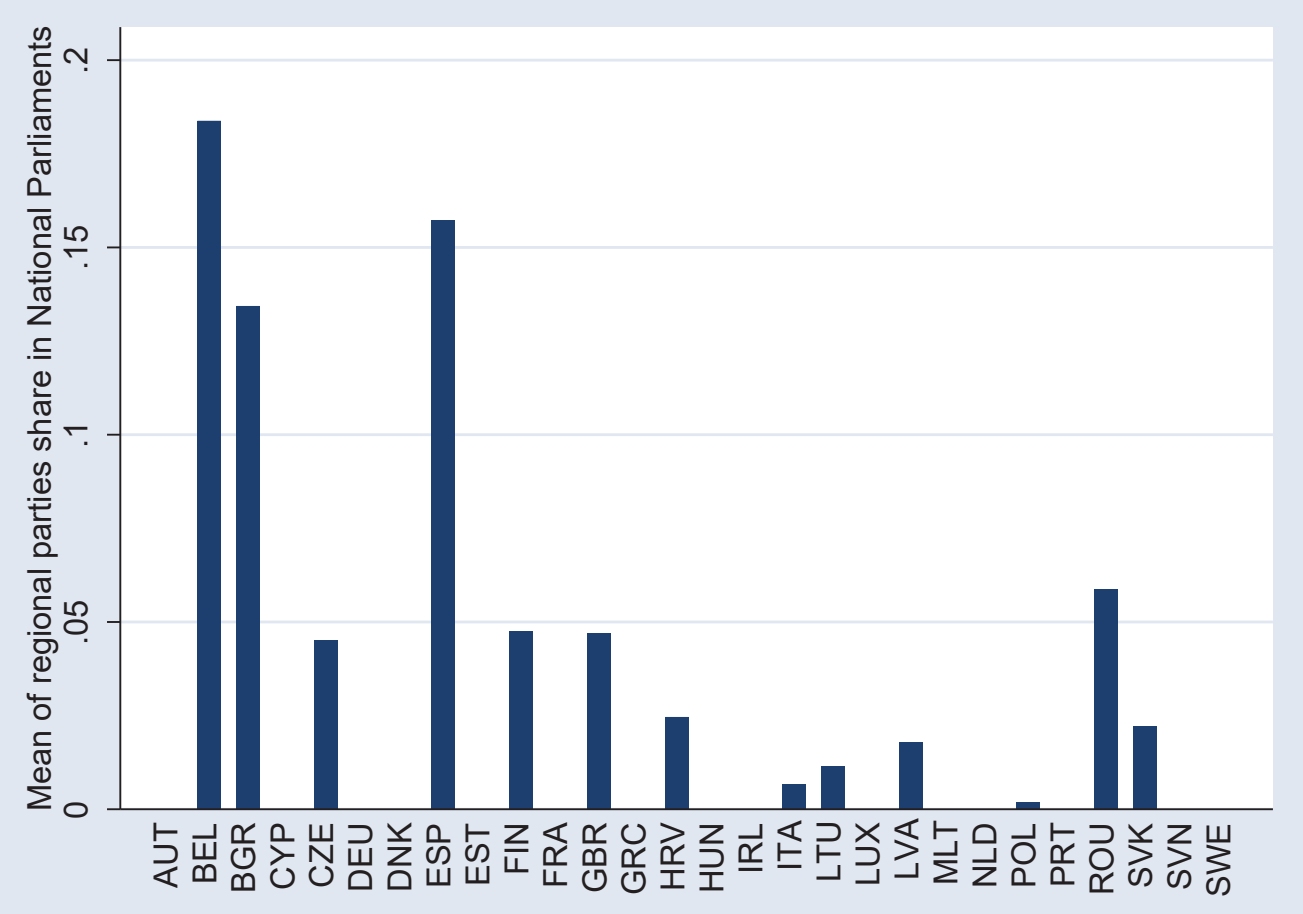

Figure 5 - Mean regional parties shares in the national parliaments (EU 28) by country. Source: own elaboration with data from Manifesto Project 2018 (Volkens et al., 2018) 